\title{
ELECTRODIAGNOSTIC EVALUATION OF CARPAL TUNNEL SYNDROME
}

\author{
ROBERT A. WERNER, MD, MS ${ }^{1}$ and MICHAEL ANDARY, MD, MS ${ }^{2}$ \\ ${ }^{1}$ University of Michigan Health System, Ann Arbor Veterans Health System, Ann Arbor, Michigan, USA \\ ${ }^{2}$ Department of Physical Medicine and Rehabilitation, College of Osteopathic Medicine, Michigan State University, \\ East Lansing, Michigan, USA \\ Accepted 14 June 2011
}

ABSTRACT: Carpal tunnel syndrome (CTS) is the most common nerve entrapment. Electrodiagnostic (EDX) studies are a valid and reliable means of confirming the diagnosis. This monograph addresses the various EDX techniques used to evaluate the median nerve at the wrist. It also demonstrates the limitations of EDX studies with a focus on the sensitivity and specificity of EDX testing for CTS. The need to use reference values for populations such as diabetics and active workers, where normative values differ from conventional cutoffs used to confirm suspected CTS, is presented. The value of needle electromyography (EMG) is examined.

Muscle Nerve 44: 597-607, 2011

Carpal tunnel syndrome (CTS) is a clinical syndrome of numbness, tingling, burning, and/or pain associated with localized compression of the median nerve at the wrist. It is the most commonly reported nerve compression syndrome, accounting for $0.2 \%$ of all U.S. ambulatory care visits in $2006^{1}$ and over 500,000 carpal tunnel releases in $2006 .^{2}$ The impairment of the median nerve within the carpal tunnel is secondary to compression of the median nerve, resulting in mechanical compression and/or local ischemia. However, the symptoms associated with CTS are frequently reported in areas outside the distribution of the median nerve.

Clinical CTS can be confirmed using electrodiagnostic (EDX) techniques that document abnormalities of the median nerve fibers within the carpal tunnel. Numerous studies have reported that comparison of sensory nerve responses is more effective than the use of an absolute median nerve latency in documenting the median nerve abnormalities consistent with CTS. ${ }^{3}$ Sensory fibers

Abbreviations: AANEM, American Association of Neuromuscular and Electrodiagnostic Medicine; AAOS, American Academy of Orthopedic Surgeons; APB, abductor pollicis brevis; CMAP, compound muscle action potential; CSI, combined summary index; CTS, carpal tunnel syndrome; EDX, electrodiagnostic; EMG, electromyography; inching, median sensory short segment stimulation across the wrist; MGA, Martin-Gruber anastomosis; MMW, median mononeuropathy at the wrist; NAP, nerve action potential; NCS, nerve conduction studies; palmdiff, median-ulnar mixed nerve palm latency difference from palm to wrist; ringdiff, median-ulnar sensory latency difference to the ring finger; SNAP, sensory nerve action potential; thumbdiff, median-radial latency difference to the thumb

Key words: carpal tunnel syndrome; electromyography; median nerve; nerve entrapment; nerve injury

This paper was reviewed and edited by committees of the AANEM. It did not undergo further review at Muscle \& Nerve.

Correspondence to: R. A. Werner, AANEM, 2621 Superior Drive NW, Rochester, MN 55901; e-mail: rmichel@aanem.org

(C) 2011 American Association of Neuromuscular and Electrodiagnostic Medicine.

Published online 15 September 2011 in Wiley Online Library (wileyonlinelibrary.com). DOI 10.1002/mus.22208

have a larger proportion of large myelinated fibers, which have a higher energy requirement, and thus are more susceptible to ischemic damage. ${ }^{4}$ Focal compression results in both ischemia and mechanical damage to the nerve fibers due to dysfunction of the myelin and disruption at the nodes of Ranvier. ${ }^{4,5}$ Together this results in slowed conduction velocity, which allows the EDX physician to confirm a focal abnormality of the median nerve within the carpal tunnel. The comparison of median sensory latency to the radial, ulnar, or median (segments outside the carpal tunnel) sensory latencies allows the greatest accuracy for confirming the clinical diagnosis. ${ }^{3}$ Use of a comparison latency, as opposed to an absolute latency, controls for confounding factors of age, temperature, disease state (i.e., diabetes), gender, and hand size. ${ }^{6}$

\section{GENERAL APPROACH TO NERVE CONDUCTION STUDIES}

Uncomplicated CTS. In all cases, median sensory nerve distal latencies should be measured and compared to either the ulnar or radial sensory latencies in the same hand. There are multiple techniques to accomplish this, most of which are described herein. Using two comparison techniques that agree (either normal or abnormal) lowers the risk of a false positive or false negative. ${ }^{7}$ Thus, two comparison techniques that clearly agree (either normal or abnormal) should be adequate to confirm the diagnosis. In cases where the testing is borderline, extra testing and/or the combined summary index (CSI), described in what follows, can help clarify the diagnosis. ${ }^{8,9}$ If the median sensory response is absent, the use of median motor latency in comparison to the ulnar motor latency can help localize the problem. When comparison nerve conduction studies (NCSs) are abnormal for CTS in one limb and that limb is the only symptomatic limb, the American Association of Neuromuscular and Electrodiagnostic Medicine (AANEM) guidelines do not recommend performing NCSs on the opposite hand. ${ }^{10}$ If the symptoms are bilateral, or more diffuse, then NCSs on the opposite side are useful. If initial comparison NCSs on the symptomatic side are normal, further NCSs are rarely needed. NCSs in 
Table 1. AANEM practice recommendations for CTS. ${ }^{10}$.

1. Standard: Sensory conduction studies across the wrist of the median nerve, and if the results are abnormal, of one other sensory nerve in the symptomatic limb.

2. Standard: If the initial median sensory nerve conduction study across the wrist has a conduction distance greater than $8 \mathrm{~cm}$ and the results are normal, additional studies as follows:

A. Comparison of median sensory nerve conduction across the wrist over a short $(7-8 \mathrm{~cm})$ conduction distance; or:

B. Comparison of median sensory conduction across the wrist with radial or ulnar sensory conduction across the wrist in the same limb; or:

C. Comparison of median sensory or mixed nerve conduction through the carpal tunnel to sensory or mixed nerve conduction studies of proximal (forearm) or distal (digit) segments of the median nerve in the same limb.

3. Guideline: Motor conduction studies of the median nerve recording from the thenar muscle and of one other nerve in the symptomatic limb to include measurement of distal latency.

4. Option: Electromyography of a sample of muscles innervated by the $\mathrm{C} 5$ to $\mathrm{T} 1$ spinal roots, including a thenar muscle innervated by the median nerve of the symptomatic limb.

5. Option: Comparison of the median motor nerve distal latency (second lumbrical) to the ulnar motor nerve distal latency (interossei)

the asymptomatic or minimally symptomatic limb are based on clinical utility, but they are not required to diagnose CTS. If a systemic problem like polyneuropathy is suspected, more widespread testing will likely help. Practice parameters for an EDX examination in CTS have been published by the AANEM $^{10}$ (Table 1). These also have been incorporated by the American Academy of Orthopedic Surgeons (AAOS) evidence-based guidelines. ${ }^{11}$

\section{MEDIAN SENSORY NERVE CONDUCTION STUDIES}

Most laboratories use antidromic sensory NCSs, because they have the advantage of producing larger amplitude sensory nerve action potentials (SNAPs) compared with orthodromic stimulation. $^{12,13}$ In addition, peak sensory latencies are preferred over onset latencies in most laboratories, because the peaks are easier to identify in many waveforms, especially when the SNAP amplitude is small and the baseline is variable. Peak latencies have a higher inter- and intrarater reliability compared with the onset latencies. ${ }^{14}$ Commonly, these latencies are measured at $14 \mathrm{~cm}$ from the digits (Fig. 1).

Comparing the median sensory distal latency to the ulnar sensory distal latency can improve sensitivity and specificity and helps to control for other confounding variables such as temperature, age, height, and other patient-specific variability. 6,10 SNAP amplitude has not been reported as reliable in the diagnosis of CTS. The sensory amplitude has considerable variability; therefore, the lower limit of normal is relatively small. In the absence of a prolonged distal latency, a low SNAP amplitude has limited localizing value, unless a normal amplitude can be obtained when stimulation is distal to the carpal tunnel (suggesting conduction block in the carpal tunnel). A prolonged finger-towrist latency can also be the result of a focal lesion distal to the carpal tunnel, such as a digital neuropathy. ${ }^{15}$ Mild slowing of median forearm sensory nerve conduction velocities has been reported in $3-9 \%$ of CTS patients. ${ }^{16-18}$

Measurement of Latency from Wrist to Palm and Palm to Wrist. The use of comparison studies and shorter segments has resulted in improved diagnostic sensitivity of NCSs for CTS. ${ }^{3}$ Because the segments of nerve outside the carpal tunnel conduct relatively normally, their inclusion in longer segments "dilutes" the sensitivity of routine methods, and a more practical method using antidromic stimulation has been used to measure the short segment across the palm (Fig. 2). ${ }^{19,20}$

The use of the distal segments of the median nerve helps distinguish CTS from peripheral neuropathy. In CTS the maximal slowing is across the wrist, whereas in peripheral neuropathy the distal segment is more abnormal. This technique also

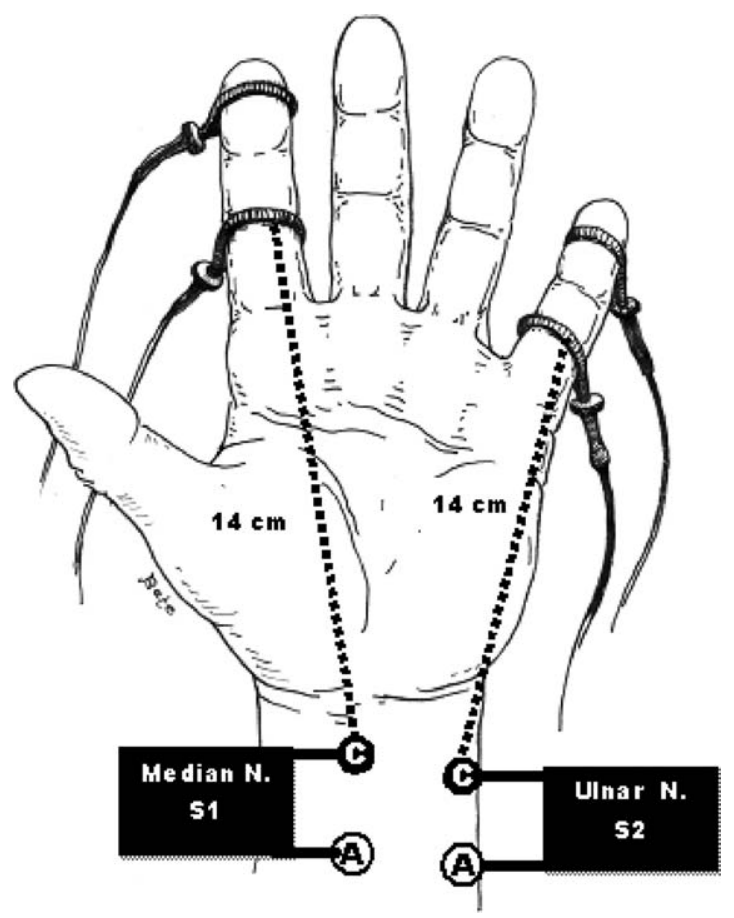

FIGURE 1. Sensory antidromic recording of the median nerve to digit 2 (S1) and the ulnar nerve to digit 5 (S2). The stimulation is at the wrist $14 \mathrm{~cm}$ proximal to the recording electrode (G1) usually placed on the index finger or middle finger. The reference electrode is a ring electrode on the distal finger. The ulnar stimulation is also $14 \mathrm{~cm}$ at the wrist with recording from the little finger and similar electrode placement as the index finger. 


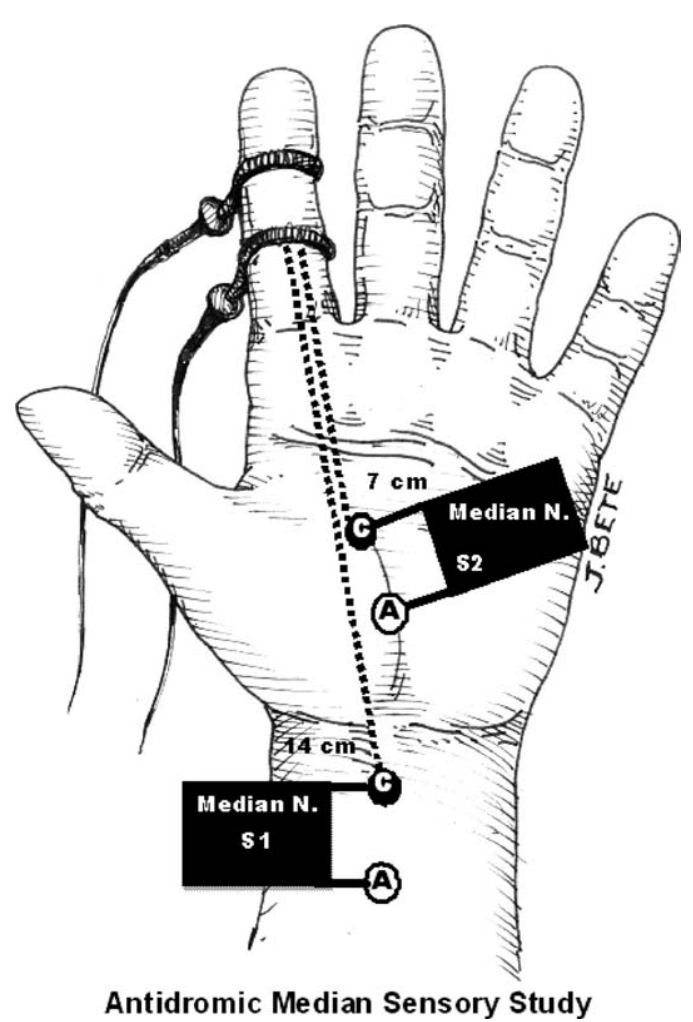

FIGURE 2. Antidromic stimulation in the palm with recording at the index finger or middle finger. Stimulation is 7 or $8 \mathrm{~cm}$ from the wrist stimulation, usually between the second and third metacarpals.

allows the EDX physician to recognize conduction block, which may be seen in acute CTS. ${ }^{21}$ Determining the exact criteria for conduction block in sensory studies is difficult, but an increase in the palm SNAP amplitude of $\geq 50 \%$ compared with wrist stimulation has been reported to suggest conduction block. ${ }^{17,18,22}$ This technique may clarify the meaning of small SNAP amplitudes at the wrist. If both stimulation sites have small amplitudes, there may be axonal loss. Neurapraxia is more likely if the amplitude of the distal response (midpalm to digit) is significantly larger than the proximal wrist SNAP amplitude.

Orthodromic Palmar Stimulation. The median and ulnar nerves are stimulated in the midpalm at a point $8 \mathrm{~cm}$ distal to the wrist recording electrodes. ${ }^{23}$ This is referred to as palmdiff, or the median-ulnar mixed nerve palm latency difference from palm to wrist (Fig. 3).

Median palmar stimulation evokes a mixed nerve action potential (NAP) from motor fibers innervating the second lumbrical muscle and the sensory digital nerve afferents from the index and middle fingers. However, the NAP recorded at the wrist is primarily generated by sensory fibers. ${ }^{23} \mathrm{~A}$ difference of $\geq 0.3 \mathrm{~ms}$ or $\geq 0.4 \mathrm{~ms}$ is considered abnormal in most laboratories (Table 2). One dis- advantage of this technique is the greater shock artifact, occasionally making it more difficult to obtain a good response, especially from the ulnar nerve.

\section{Median-Ulnar Sensory Latency Difference to the Ring}

Finger. Known as ringdiff, this is usually an antidromic technique to stimulate the median and ulnar nerve at the wrist and record $14 \mathrm{~cm}$ from the ring finger using ring electrodes. The ring finger has median and ulnar innervation, and thus comparison of these latencies can be an efficient method of establishing a relative slowing of the median nerve compared with the ulnar across the wrist (Fig. 4).

A difference between the median and ulnar nerve latencies of $\geq 0.4 \mathrm{~ms}$ or $\geq 0.5 \mathrm{~ms}$ is considered significant (Table 1). The median nerve fibers to the ring finger may be more subject to compression due to the position of ring finger fibers in the outer margin of the median nerve beneath the transverse carpal ligament. Because the SNAP amplitudes are small, the median response may be absent in more severe cases of CTS.

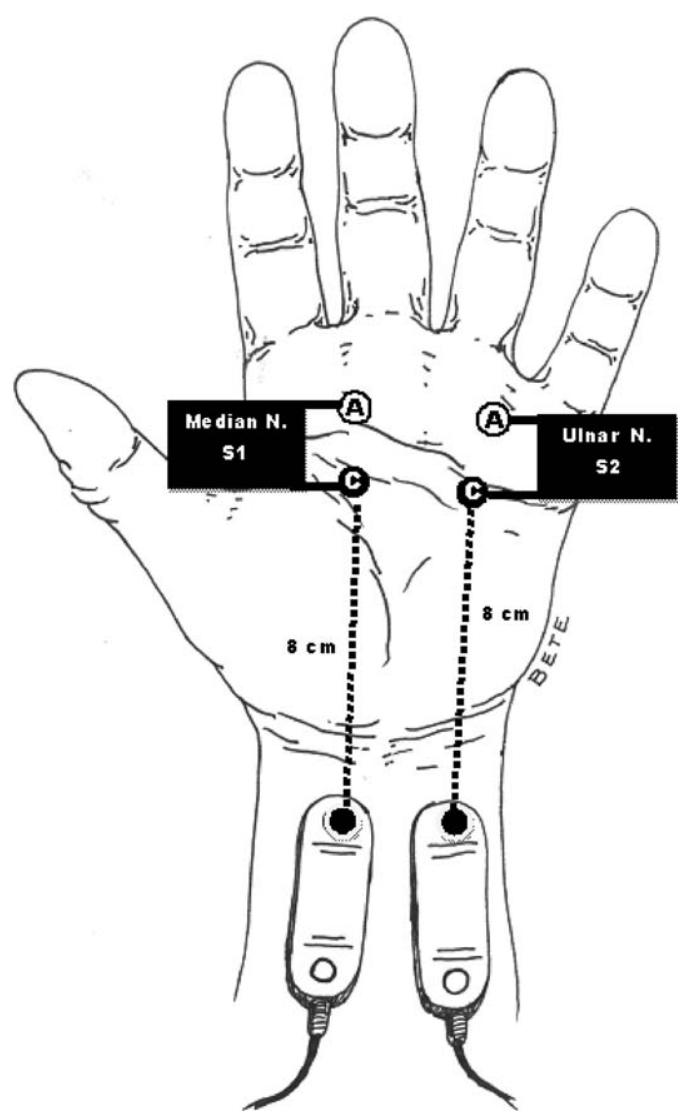

FIGURE 3. Median-ulnar mixed nerve palm latency difference from palm to wrist (also known as palmdiff). Stimulation is in the palm over the median (S1) or ulnar (S2) nerve, $8 \mathrm{~cm}$ distal to the active recording electrode. Recording is made with a bar electrode at the wrist over the course of the median and ulnar nerves, respectively. ${ }^{23}$

MUSCLE \& NERVE October 2011

599 
Table 2. Review of existing studies and their suggested upper limits of normal..

\begin{tabular}{|c|c|c|c|}
\hline Comparison & Technique & Investigator & $\begin{array}{c}\text { Threshold defining } \\
\text { abnormal }\end{array}$ \\
\hline \multicolumn{4}{|l|}{ Sensory nerve responses } \\
\hline Median-median & $\begin{array}{l}\text { Short segment, } 1 \mathrm{~cm} \text {, } \\
\text { antidromic (inching) }\end{array}$ & $\begin{array}{l}\text { Kimura, } 1979^{68} \\
\text { Andary et al., } 1992^{69}\end{array}$ & $\geq 0.5 \mathrm{~ms}$ \\
\hline & & Nathan et al., $1988^{27}$ & $\geq 0.4 \mathrm{~ms}$ \\
\hline Median-ulnar & Digit 2 to digit $5,14 \mathrm{~cm}$, antidromic & Felsenthal and Spindler, $1979^{19}$ & $\geq 0.5 \mathrm{~ms}$ \\
\hline $\begin{array}{l}\text { Median-ulnar(normalized } \\
\text { for active workers) }\end{array}$ & Digit 2 to digit $5,14 \mathrm{~cm}$, antidromic & Salerno et al., $1998^{14}$ & $\geq 0.8 \mathrm{~ms}$ \\
\hline $\begin{array}{l}\text { Median-ulnar (normalized } \\
\quad \text { for mild diabetics) }\end{array}$ & Digit 2 to digit $5,14 \mathrm{~cm}$, antidromic & Albers et al., $1996^{52}$ & $\geq 1.0 \mathrm{~ms}$ \\
\hline \multirow[t]{2}{*}{ Median-ulnar (ringdiff) } & Digit 4, $14 \mathrm{~cm}$, antidromic & $\begin{array}{l}\text { Johnson et al., } 1981^{70} \\
\text { Jackson and Clifford, } 1989^{71}\end{array}$ & $\geq 0.4 \mathrm{~ms}$ \\
\hline & & $\begin{array}{l}\text { Robinson et al., } 1998^{8} \\
\text { Uncini et al., } 1989(13 \mathrm{~cm})^{72} \\
\text { Andary et al., } 1992^{69}\end{array}$ & $\geq 0.5 \mathrm{~ms}$ \\
\hline \multirow[t]{2}{*}{ Median-ulnar (palmdiff) } & Midpalmar, $8 \mathrm{~cm}$, orthodromic & $\begin{array}{l}\text { Stevens et al., } 1987^{17} \\
\text { Robinson et al., } 1998^{8} \\
\text { Andary et al., } 1992^{69}\end{array}$ & $\begin{array}{l}\geq 0.2 \mathrm{~ms} \\
\geq 0.3 \mathrm{~ms}\end{array}$ \\
\hline & & Jackson and Clifford, $1989^{71}$ & $\geq 0.4 \mathrm{~ms}$ \\
\hline \multirow[t]{2}{*}{ Median-radial (thumbdiff) } & $\begin{array}{l}\text { Digit } 1,10 \mathrm{~cm} \text {, antidromic } \\
\text { or orthodromic }\end{array}$ & $\begin{array}{l}\text { Redmond and Rivner, } 1988^{73} \\
\text { Johnson et al., } 1987^{74} \\
\text { Carroll et al., } 1987^{24} \\
\text { Robinson et al., } 1998^{8}\end{array}$ & $\begin{array}{c}0.5 \mathrm{~ms} \\
\geq 0.5 \mathrm{~ms}\end{array}$ \\
\hline & & $\begin{array}{l}\text { Jackson and Clifford, } 1989^{71} \\
\text { Andary et al., } 1992^{69}\end{array}$ & $\geq 0.4 \mathrm{~ms}$ \\
\hline \multicolumn{4}{|l|}{ Motor nerve responses } \\
\hline Median-ulnar & $\begin{array}{l}\text { Median-to-thenar compared with } \\
\text { ulnar-to-hypothenar }\end{array}$ & Kimura, $1983^{20}$ & $\geq 1.5 \mathrm{~ms}$ \\
\hline Median-ulnar & $\begin{array}{l}\text { Median-to-lumbricals compared } \\
\text { with ulnar-to-intrinsics }\end{array}$ & Preston and Andary, $1992^{32}$ & $>0.4 \mathrm{~ms}$ \\
\hline Median-ulnar & $\begin{array}{l}\text { Median-to-thenar compared } \\
\text { with ulnar-to-thenar }\end{array}$ & Sander et al., $1999^{30}$ & $>0.8 \mathrm{~ms}$ \\
\hline
\end{tabular}

Median-Radial Latency Difference to the Thumb. Known as thumbdiff, these SNAPs are acquired similar to the ringdiff technique described previously with ring electrodes on the thumb (digit 1) but typically using only a $10-\mathrm{cm}$ distance from stimulation to recording (Fig. 5).

Thumb position can alter this measurement, and the thumb should be extended. The cutoff for the median-radial latency difference using antidromic stimulation and a $10-\mathrm{cm}$ distance for each nerve is $\geq 0.4$ or $\geq 0.5 \mathrm{~ms}^{24,25}$ The radial nerve is less prone to injury, and therefore comparing the medial to the radial sensory segments is useful in patients with concomitant ulnar nerve injury.

Median Sensory Short Segment Stimulation across the Wrist. Using this technique, called inching, the median nerve is stimulated in serial $1-\mathrm{cm}$ increments across the carpal tunnel with antidromic recording from the index or middle fingers (Fig. 6). ${ }^{26,27}$

For routine use, eight or even fewer stimulation sites are sufficient, and a segmental peak latency difference of $\geq 0.5 \mathrm{~ms}$ is considered abnormal. ${ }^{27} \mathrm{~A}$ drop in amplitude can be used to document conduction block. Although inching is a reliable method, it has the disadvantages of being time-consuming and uncomfortable, because multiple sites are stimulated. In addition, this technique can be difficult to record because of stimulation artifact. In those patients with thick skin or a thick transverse ligament between the stimulation point and median nerve, the strong stimulus intensity required to adequately stimulate the nerve makes the exact site of nerve depolarization uncertain. $^{17,18}$ The short segments also accentuate any measurement error that can occur with marking the segments or change in position of the stimulator when placed upon the skin surface.

csı. Robinson and colleagues have used the sum of the three comparison tests just described to improve the reliability as well as the sensitivity and specificity of NCS to diagnose CTS. CSI = thumbdiff + ringdiff + palmdiff. Abnormal is defined as $\geq 0.9$ $\mathrm{ms}$ and has a sensitivity of $83 \%$ and specificity of $95 \%$. If the cutoff was raised to $1.1 \mathrm{~ms}$, the sensitivity dropped to $82 \%$, but specificity was found to improve up to $100 \%$ in one data set. $^{8}$ Subsequent studies have demonstrated that if the first comparison (regardless of which of the possible three comparisons is chosen) has a significant latency difference, then it is not necessary to perform all three comparisons, because, when the first comparison is 


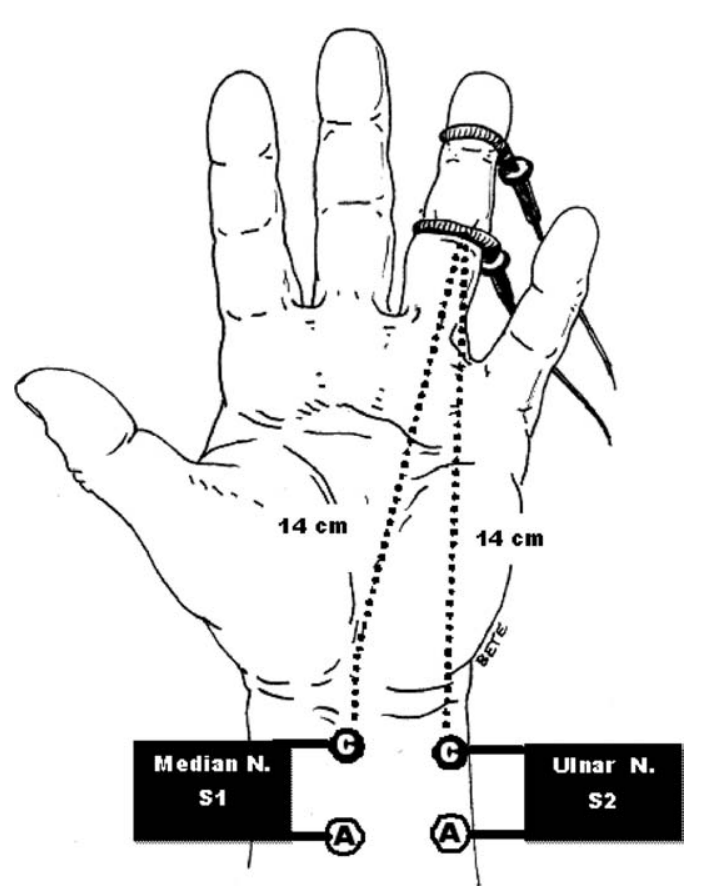

FIGURE 4. Median-ulnar sensory latency difference to the ring finger (also known as ringdiff). Stimulation is $14 \mathrm{~cm}$ proximal to the G1 ring electrode, over the median (S1) or ulnar (S2) nerves at the wrist. Recording is made with ring electrodes on the ring finger. ${ }^{23}$

clearly abnormal, there is a $98 \%$ likelihood that the CSI will also be abnormal. ${ }^{9}$ If the first comparison does not meet the critical threshold, it is very useful to use the full CSI. In addition, a retrospective trial

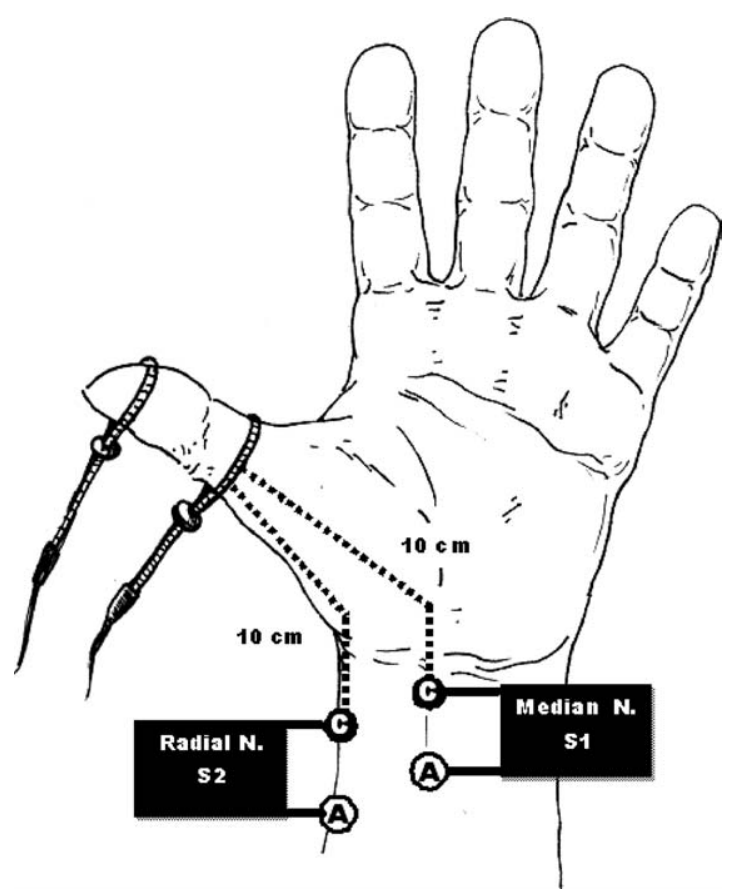

FIGURE 5. Median-radial sensory latency difference to the thumb (also known as thumbdiff). Stimulation is over the median (S1) and radial (S2) nerves at the wrist, $10 \mathrm{~cm}$ proximal to ring electrodes. Recording is made with ring electrodes on the thumb.

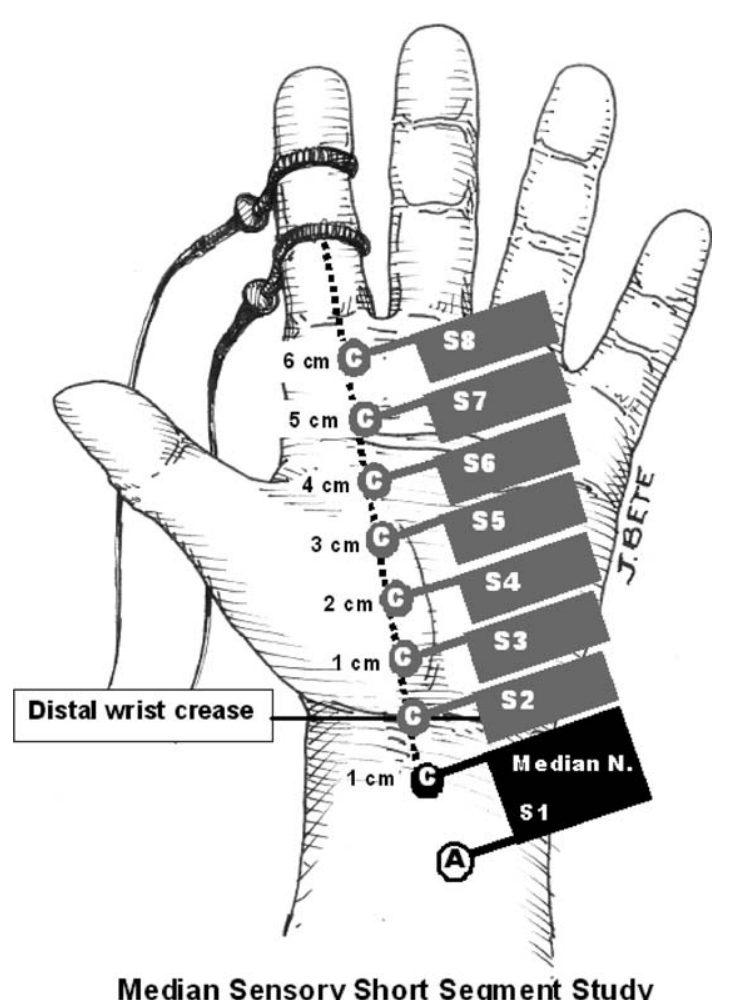

FIGURE 6. Median-sensory short segment stimulation (also known as inching). Stimulation starts $1 \mathrm{~cm}$ proximal to the distal wrist crease and continues segmentally in $1-\mathrm{cm}$ increments to 6 $\mathrm{cm}$ distal to the wrist crease for a total of eight stimulations of the median nerve (S1-S8). Recording is made with ring electrodes on the index finger or middle finger.

demonstrated that patients with a CSI between 2.5 and 4.6 had somewhat better surgical outcomes. ${ }^{28}$

The use of multiple comparisons for the evaluation of a focal entrapment may increase the risk of a type 1 error (false-positive result). ${ }^{29}$ Alternatively, the finding of more than one abnormality when evaluating the median nerve across the wrist would lower the possibility of a type 1 error. $^{7}$ Any attempt to increase the sensitivity of a testing paradigm will have the impact of lowering the specificity of the testing.

\section{MEDIAN MOTOR NERVE CONDUCTION STUDIES}

Although less sensitive than the other diagnostic methods just described, motor nerve stimulation still plays an important role in the documentation of motor fiber involvement and can be used to localize the lesion when the median sensory potentials are absent. The median motor distal latency is obtained by recording over the abductor pollicis brevis (APB) with stimulation at the wrist (Fig. 7).

This latency can be compared with the ulnar motor distal latency to the hypothenar eminence. There is some controversy regarding the appropriate cutoff. Most laboratories define a prolonged median motor latency if the relative latency is $\geq 1.2-1.8 \mathrm{~ms}^{30,31}$ The use of shorter cutoff values likely will increase the rate of false positives. 


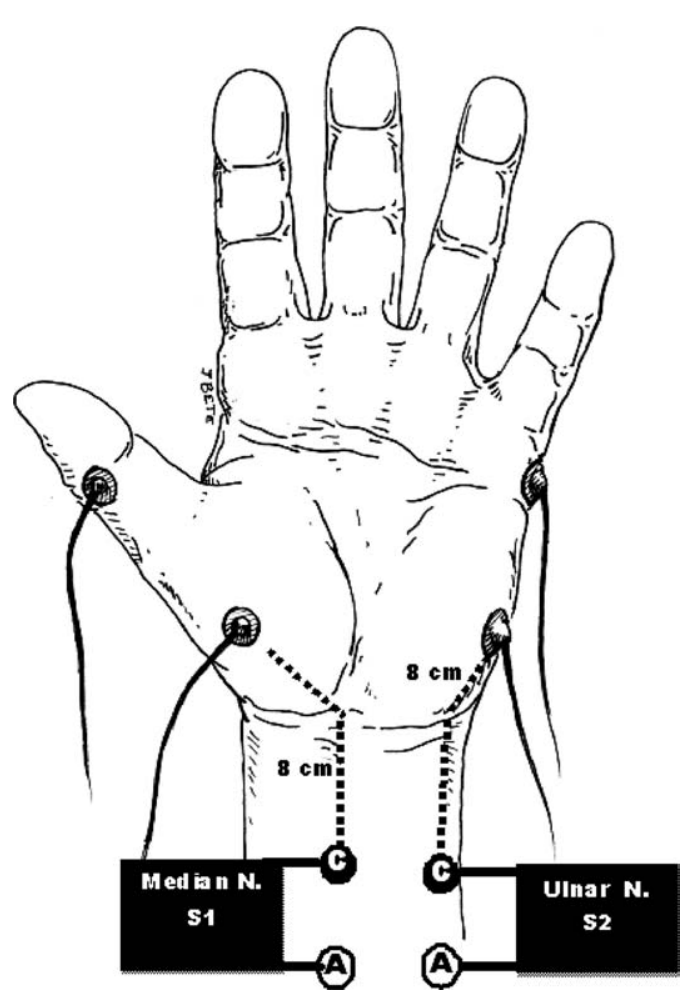

FIGURE 7. Electrode placement for evoking the median-thenar (S1) and ulnar-hypothenar (S2) compound muscle action potentials.

Median-Thenar to Ulnar-Thenar Latency Difference. This is a simple motor comparison technique in which the first step is the standard median motor technique just described. The ulnar nerve can be stimulated $1 \mathrm{~cm}$ proximal to the distal wrist crease, and a compound muscle action potential (CMAP) can be recorded with volume conduction from other ulnar-innervated thenar area muscles (adductor pollicis and flexor pollicis brevis). This technique is useful in patients with Riche-Cannieu anastomosis, where the opponens and APB may also have some ulnar innervation (Fig. 8).

The ulnar nerve waveform usually has an initial positive deflection, and the latency should be taken from this point. Some investigators reported an abnormal value of $>0.8 \mathrm{~ms} .{ }^{30}$ They cautioned against the use of $>0.8 \mathrm{~ms}$, as this would increase the false positives due to finding median-ulnar motor latency differences up to $1.4 \mathrm{~ms}$ in patients who may not have CTS. This may be related to the difficulty in determining the exact "take off" for the CMAP. ${ }^{32}$

Lumbrical and Interossei Recording. Another relatively simple motor comparison technique records a median CMAP latency from the second lumbrical and an ulnar CMAP latency from the interossei (Fig. 9). ${ }^{33-35}$

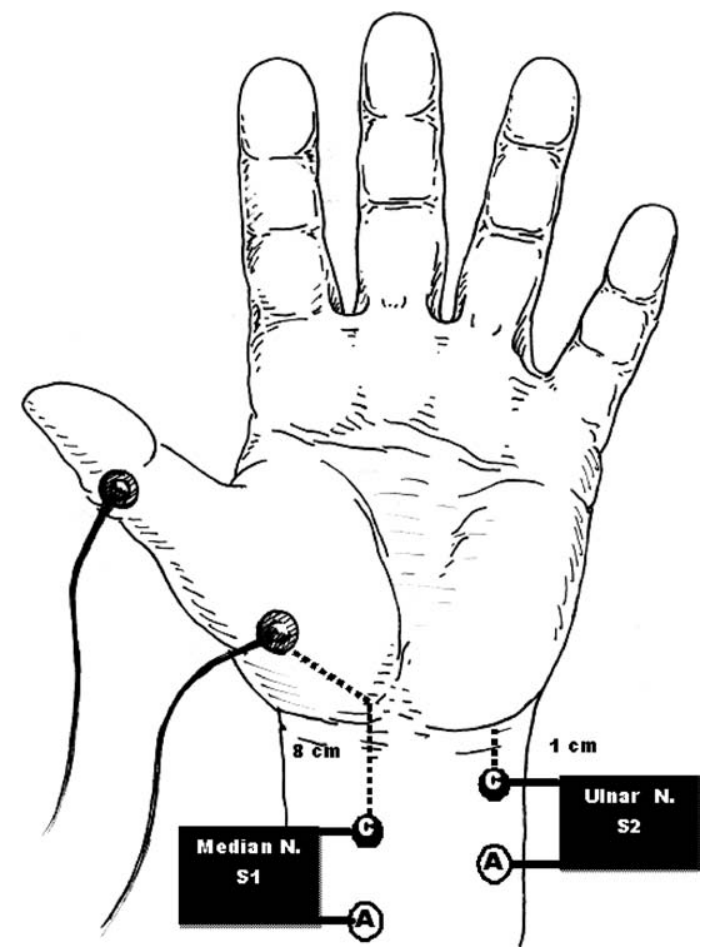

FIGURE 8. Electrode placement for evoking the median-thenar (S1) to ulnar-thenar (S2) latency difference (TTLD). The second stimulation is over the ulnar nerve, and the recording is over the thenar muscles.

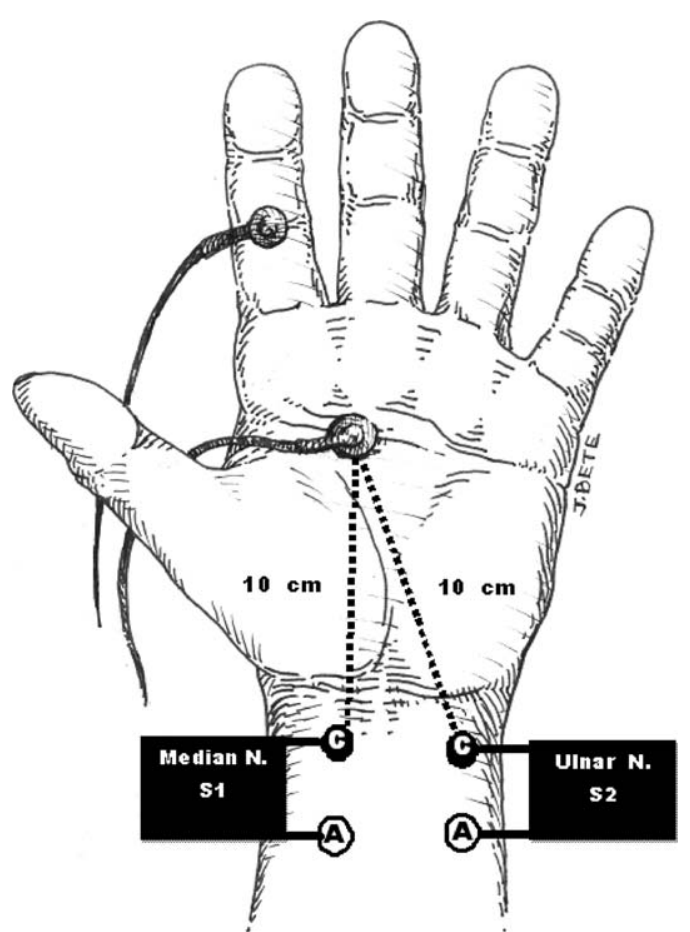

FIGURE 9. Median-ulnar motor latency difference to intrinsics. Stimulation is at the wrist, with the same distance (usually 9-10 $\mathrm{cm}$ ) proximal to $\mathrm{G} 1$ along the course of the median (S1) and ulnar (S2) nerves. Recording is at G1 between the second and third metacarpals in the distal third of metacarpals. Median stimulation records from the second lumbrical, while ulnar stimulation records primarily from the interossei. The G2 is over the proximal interphalangeal joint of the index finger. 
A difference of $>0.4 \mathrm{~ms}$ between the median and ulnar latencies has been reported as significant. $^{32}$ In that study, the investigators cautioned the possibility of false positives using this number, as they have noted larger differences in those who were believed to be normal. In addition, because the median fibers to the second lumbrical are relatively spared compared with fibers to the thenar muscles, this technique may help with diagnosis of severe CTS when a lumbrical response may be obtained when other responses are absent (i.e., the median CMAP when recorded over the APB). ${ }^{18,36,37}$

Midpalm Motor Stimulation. Information about the presence or absence of conduction block at the carpal tunnel can be obtained by recording the change in amplitude after stimulation of motor fibers in the palm and at the wrist. ${ }^{38}$ This technique must be used with caution, because the distal stimulation in the palm can also stimulate ulnar-innervated fibers to the thenar muscles or result in direct muscle stimulation, thus demonstrating a false-positive conduction block. Care should be used to look for a positive dip when performing the palm stimulation, which would suggest stimulation of ulnar-innervated muscles in the thenar eminence.

Martin-Gruber Anastomosis. The Martin-Gruber anastomosis (MGA) is an anatomic anomaly observed in 7-34\% of the population. Motor fibers usually cross from the anterior interosseous nerve (a branch of the median nerve) to the ulnar nerve and enter the hand with the ulnar nerve going through the Guyon canal and bypassing the carpal tunnel. Many muscles in the hand can be innervated by these fibers, but the first dorsal interosseous is the most commonly reported. ${ }^{39}$ The MGA usually is clinically irrelevant; however, it can confuse the interpretation of the motor NCS, thus knowledge of the patterns is helpful. Because MGA fibers are only motor, sensory studies are not affected. Findings that are seen include: (1) larger amplitude of the median CMAP at the elbow than the CMAP at the wrist; (2) initial positive (downward) deflection of the CMAP at the elbow; and (3) spurious and falsely fast median nerve conduction velocity between elbow and wrist. The positive deflection from the elbow usually occurs when there is both CTS and MGA, because the MGA fibers that pass through the Guyon canal are faster than the slowed median fibers going through the carpal tunnel. This initial positive deflection with median elbow stimulation comes from the distant ulnar-innervated muscles in the thenar eminence and not from the APB. In severe CTS the velocity can be calculated as $>100 \mathrm{~m} / \mathrm{s}$, and in extreme cases the latency from the elbow to the thenar
CMAP can be faster than the median latency from the wrist to thenar. ${ }^{39}$

We have not found any published cases in which the motor latency is abnormal and the comparison sensitive sensory studies described are normal. There are cases of recurrent branch median motor neuropathy at the wrist, but this is not the same as CTS. If the distal motor latencies are abnormal when sensory nerve latencies are normal, extra care is required to exclude other causes, such as a C8-T1 radiculopathy, anterior horn cell disease, recurrent branch median neuropathy, or multifocal motor neuropathy, by reviewing the clinical findings and by performing additional NCSs and needle electrode examinations. Usually, isolated abnormalities of median motor nerve conduction with a normal median sensory NCS are not due to CTS.

A summary of studies and the suggested cutoff values for common sensory and motor comparison studies are presented in Table 2.

Conduction Velocity in the Forearm. Some patients with more severe CTS have slowing in the forearm proximal to the carpal tunnel. The etiology for this is unclear. The two major theories are: (1) retrograde degeneration of the median nerve proximal to the wrist; and (2) conduction block of the fastest conducting fibers at the carpal tunnel. ${ }^{18,39}$ The finding of slowed conduction velocity in the forearm does not rule out the diagnosis of CTS. The EDX physician must be aware that this finding is not rare in patients with a strong clinical impression of CTS.

Other Methods. Median nerve latencies across the wrist may increase in cases of borderline CTS after 2-5 minutes of wrist flexion ${ }^{40,41}$ or after $10-15$ minutes of intensive hand activity. Unfortunately, the latencies also increase in normal subjects to a similar extent. ${ }^{42}$ The current AANEM guidelines do not recommend inclusion of these methods in the routine evaluation of patients suspected to have CTS. ${ }^{10}$

Comparison of Different Techniques. Although sensory comparison techniques have been shown to be more sensitive and specific than absolute sensory distal latencies, no one comparison technique has been clearly shown to be better than another. ${ }^{3,43}$

Sensitivity and Specificity of NCSs for CTS. A consensus conference employed to refine the epidemiologic case definition of CTS concluded that there is no "gold standard" for the diagnosis of CTS, and therefore attempts at defining sensitivity and specificity are estimates at best. There are multiple problems in methodology including variable reference standards and spectrum bias in case- 
control studies. ${ }^{43,44}$ Rempel and colleagues ${ }^{44}$ concluded that the combination of EDX study findings and characteristic symptoms was the most accurate method to establish the diagnosis. They recognized that EDX studies could not be used as a gold standard for establishing the diagnosis. Approximately $10-15 \%$ of subjects with clinical CTS will have normal NCSs, which reflects a sensitivity of $85-90 \%$. There are patients with intermittent symptoms that did not result in demyelination or axon loss as measured using NCSs. These symptoms are most likely related to acute ischemia with associated conduction block and are rapidly reversible (both symptoms and EDX findings). This has been demonstrated in experimental use of external compression of the median nerve in the carpal tunnel. ${ }^{45}$ Many EDX physicians want to improve the sensitivity of their evaluation of patients suspected of having CTS, but this will influence the specificity of the test. What is frequently overlooked by EDX physicians is the finding that the specificity of EDX testing is only $82-85 \%$ in certain populations (i.e., there is a $15-18 \%$ chance of a false positive). ${ }^{3,46-48}$ This can be a major issue when evaluating workers with hand-intensive jobs who have vague hand symptoms but have a higher false-positive rate for a median mononeuropathy at the wrist $(\mathrm{MMW}) .{ }^{46,48}$

Predictive Value of an Abnormal Median Nerve Latency across the Wrist in Asymptomatic Subjects. The meaning of an abnormal median NCS across the wrist in someone with no symptoms suggestive of CTS has been questioned. It is reasonable to ask if these subjects were preclinical cases of CTS. A welldesigned prospective case-control study compared asymptomatic workers, with and without an MMW, to determine if they would proceed to develop symptoms consistent with CTS. Cases were defined as asymptomatic workers with prolongation of $\geq 0.5 \mathrm{~ms}$ of the median sensory distal latency compared with the ipsilateral ulnar sensory latency (14 cm, antidromic). Control subjects were age- and gender-matched asymptomatic workers from the same work site with a median-to-ulnar sensory peak difference of $\leq 0.2 \mathrm{~ms}$ and with both the median and ulnar absolute latencies within normal limits. After 2 years, asymptomatic workers with a prolonged median SNAP were no more likely to develop symptoms consistent with CTS than workers with a normal median sensory nerve latency. When these workers were subsequently followed for a total of 6 years, an increased risk of developing CTS symptoms was found for subjects who had an earlier abnormal median sensory nerve latency. ${ }^{49,50}$ These findings are very similar to those of another trial with an 11-year follow-up of industrial workers. ${ }^{51}$ In each study, approximately $25 \%$ of asymptomatic workers with an abnormal median NCS across the wrist developed symptoms of CTS. However, $75 \%$ of workers with an abnormal median sensory latency at baseline did not develop symptoms of CTS within 7-11 years after the initial evaluation.

Defining CTS in Special Populations. A few studies using large reference populations have proposed different cutoff values for defining CTS in specific non-normal populations (e.g., diabetics and assembly-line workers). Among mild diabetics, without symptoms suggestive of CTS, a large multicenter trial demonstrated that the upper limit of normal (2 SD above the mean) was $1.0 \mathrm{~ms}$ when comparing median and ulnar latency (digits 2 and 5, $14 \mathrm{~cm}$, antidromic). ${ }^{52}$ If a typical cutoff of $0.5 \mathrm{~ms}$ is used for diabetic patients, it would result in a large number of false positives, because patients with a relative latency of $0.5-1.0 \mathrm{~ms}$ are actually normal for this reference population. The diagnosis of CTS in diabetics is more difficult, and values obtained from normal populations can be misleading. These investigators suggested using comparison techniques with larger differences than those used in normal populations (e.g., $\geq 1.0 \mathrm{~ms}$ for diabetics). Antidromic midpalm sensory responses to the index finger may show selective slowing in the carpal tunnel when compared with the distal palm, as discussed earlier. Similarly, in a large cohort of $>300$ active assembly and clerical workers (asymptomatic workers-subjects with diabetes, rheumatoid arthritis, and thyroid conditions-were excluded, as were workers with highly hand-intensive jobs), the upper limit of normal for this reference population was $0.8 \mathrm{~ms}$ (comparison of the median and ulnar, digits 2 and $5,14 \mathrm{~cm}$, antidromic). ${ }^{14}$ This is a much larger cohort of normal subjects compared with most normative data collected for a specific laboratory, and caution should be used in defining an abnormality when evaluating an active worker with moderate slowing of the median nerve relative to the ulnar (i.e., only $0.5-$ $0.7 \mathrm{~ms}$ ). The diagnosis still is based on the clinical presentation. However, if the patient has vague hand symptoms that do not clearly define CTS and they have a borderline slowing of the median nerve (i.e., a relative latency of $0.5-0.7 \mathrm{~ms}$ ), this should not be defined as CTS. Because half of the patients in the USA diagnosed with CTS have a surgical release of the carpal tunnel for management of the condition, EDX physicians should be pay particular attention what they write in the EDX report. If a patient has a confirmed diagnosis of a peripheral neuropathy, the use of a more conservative cutoff should be considered similar to the situation described earlier in diabetic patients. CTS 
still can be diagnosed if the median motor and sensory distal latencies are disproportionately prolonged compared with the ulnar or radial latencies. Unfortunately, firm guidelines for interpretation of NCSs using exact numbers in the setting of peripheral neuropathy and other diseases are not available.

NCSs after Surgery. NCSs performed after surgery usually normalize but may not become completely normal. The exact timing of the improvement is not documented clearly, but it appears that some patients improve immediately ${ }^{53-55}$; however, improvement in NCSs can take as long as 42 weeks for sensory latencies. ${ }^{56}$ These slowed, but improved, distal latencies persist for at least 1 year and probably forever, even if symptoms are resolved. ${ }^{18,57}$ It has been suggested that the almost immediate relief of symptoms after surgery is the result of a reduction in spontaneous activity generated by the compressed nerve segment rather than by recovery from the conduction block. ${ }^{58}$

\section{NEEDLE ELECTRODE EXAMINATION}

The decision whether to perform needle electromyography (EMG) in patients with CTS is not agreed upon universally and is listed as an option in the AANEM practice parameter. ${ }^{10,59}$ If the EDX consultant is not concerned about possible cervical radiculopathy, plexopathy, or other focal mononeuropathies and the possibility of axon loss will not alter management, then needle EMG is not necessary. If the median nerve conduction across the wrist is normal, there is a very low yield for an abnormal finding on needle examination of the APB. ${ }^{60}$ Abnormal median NCSs do not predict abnormal needle EMG findings. ${ }^{59}$ Nevertheless, there are many situations in which needle EMG may add useful information to the test. Needle EMG can help and is usually necessary to diagnose cervical radiculopathy, proximal median neuropathy, or polyneuropathy in addition to documenting axon loss in CTS. These diagnoses may be in addition to, or instead of, CTS. Patients with weakness of the APB, atrophy of the thenar eminence, or reduced amplitude of the median CMAP would benefit from needle examination to document axonal loss. In some situations, the only way to document axonal loss is with needle EMG of the median-innervated thenar muscles. The findings may indicate axon degeneration, including fibrillation potentials, large motor unit potentials, or excessive polyphasic motor unit potentials.

\section{STANDARDS FOR DETERMINING THE DIAGNOSIS AND SEVERITY OF CTS}

EDX findings are commonly used to grade the severity of CTS but lack scientific rigor. The corre- lation between severity of NCSs and symptoms is not well established. ${ }^{61,62}$ However, the degree of abnormality can partially predict the outcome of surgery, with normal studies and very severe studies being worse after surgery. ${ }^{63}$ The use of these classification scales have been discouraged for several reasons, primarily because treatment may be driven by the NCS when symptoms and other factors should be more important. ${ }^{64}$

Despite these problems, the scale proposed in what follows has been used and works within the more complicated six-level scale proposed by Bland. $^{18,63}$

Mild CTS_Prolonged (relative or absolute) sensory latencies with normal motor studies. No evidence for axon loss.

Moderate CTS-Abnormal median sensory latencies as noted for mild CTS, and (relative or absolute) prolongation of median motor distal latency. No evidence of axon loss.

Severe CTS-Any of the aforementioned NCS abnormalities with evidence of axon loss as defined by either: (1) an absent or low-amplitude SNAP or mixed NAP; (2) a low-amplitude or absent thenar CMAP; or (3) a needle EMG with fibrillation potentials or motor unit potential changes (largeamplitude, long-duration motor unit potentials, or excessive polyphasics). The NCS amplitude abnormalities may be due to severe conduction block, which is not axonotmesis. This can be assessed by antidromic midpalm sensory conduction to the digits. If the SNAP at the wrist is absent or very low and the midpalm amplitude is much greater, this suggests conduction block and not axon loss. Midpalm motor conduction must be cautiously approached, because midpalm motor stimulation can easily stimulate the deep ulnar nerve fibers in the palm or Riche-Cannieu fibers that will indicate apparent motor neurapraxia. Sensory fibers are much more reliable for midpalm stimulation.

\section{INTERPRETATION OF EDX FINDINGS}

After the EDX data are collected, interpretation of the test findings is critical. There is variability among physicians about how to interpret and differentiate between normal, abnormal, or borderline studies. Age, limb temperature, skin thickness, coexisting medical conditions, and multiple other issues confound these decisions. Separation of the EDX abnormalities into the specific diagnosis of CTS distinct from other diagnoses-such as polyneuropathy, proximal median neuropathy, recurrent median neuropathy, or radiculopathy-is another aspect of the interpretation. The categorization of the median nerve injury (i.e., demyelinating or axonal) is important because some physicians will make a clinical management decision 
based on the specific type of injury documented. The AAOS guidelines ${ }^{11}$ list early surgery without conservative treatment as an option in patients with axon loss. Thus, treatment may be altered based on whether patients have demyelination or axonal loss.

Differentiating "carpal tunnel syndrome" from "median mononeuropathy at the wrist" (MMW) is a significant issue. Most definitions of CTS require symptoms that are related to median nerve dysfunction in the carpal tunnel. Thus, patients with symptoms of CTS and supportive EDX testing can be defined as confirmed CTS. Patients with abnormal NCSs but no symptoms probably should not be labeled as CTS but rather as MMW cases. This is especially important when evaluating patients with a high body mass index. There is a strong association between obesity and MMW (but not CTS). The reason for this association is not fully understood, but the relationship has been confirmed in several studies and can confound the diagnosis of CTS. ${ }^{65-67}$ If a patient has vague hand and/or wrist symptoms that do not seem related to the median nerve dysfunction at the wrist, physicians should be cautious in labeling these patients with CTS even if MMW is present. Calling this CTS may be misleading and lead to ineffective treatments. On occasion, the EDX test is normal in patients with classical CTS symptoms. In these cases, the test is likely a false negative and the patient still has CTS that has not been confirmed with EDX testing. This can be explained in the report.

Some EDX physicians formulate treatment recommendations as part of their EDX consultation, whereas others do not. Making treatment recommendations requires physicians to use their skills as a physician and utilize clinical information specific to that patient that will affect treatment decisions. These include but are not limited to disability, previous treatments, patient preferences, severity of symptoms, coexisting medical and psychological conditions, financial considerations, and quality of life. Noting that some or all of the symptoms are due not only to CTS but also to another problem, such as arthritis, tendonitis, or radiculopathy, can be part of the consultation. Treatment recommendations are usually beyond the direct EDX data collection and interpretation but are frequently included in the medical consultation. The emphasis of the report may differ depending upon the target audience. A hand surgeon is likely to want different information than a primary care doctor.

\section{CONCLUSIONS}

In the majority of cases, a careful history and physical examination are sufficient to make a clinical diagnosis of CTS and make initial treatment decisions. However, many patients present with multiple problems and/or their presentation is atypical. An EDX examination can confirm the clinical impression of CTS, which is reassuring for both the patient and physician. Other patients may have coexisting or confounding diagnoses that EDX testing and consultation can help sort out. Performing, interpreting, and reporting high-quality and evidence-based EDX testing can potentially lead to improved outcomes in many patients.

\section{REFERENCES}

1. Schappert SM, Rechtsteiner EA. Ambulatory medical care utilization estimates for 2006. Natl Health Stat Report 2008;6:1-29.

2. Cullen KA, Hall MJ, Golosinskiy A. Ambulatory surgery in the United States, 2006. Natl Health Stat Report 2009;28:1-25.

3. Jablecki CK, Andary MT, So YT, Wilkins DE, Williams FH. Literature review of the usefulness of nerve conduction studies and electromyography for the evaluation of patients with carpal tunnel syndrome. Muscle Nerve 1993;16:1392-1414.

4. Sunderland S. Nerves and nerve injuries. New York: Churchill Livingstone; 1978. p 15.

5. Gilliatt RW, Sears TA. Sensory nerve action potentials in patients with peripheral nerve lesions. J Neurol Neurosurg Psychiatry 1958; 21:109-118.

6. Salerno DF, Werner RA, Albers JW, Becker MP, Armstrong TJ, Franzblau A. Reliability of nerve conduction studies among active workers. Muscle Nerve 1999;22:1372-1379.

7. Dorfman LJ, Robinson LR. AAEM minimonograph \#47: Normative data in electrodiagnostic medicine. Muscle Nerve 1997;20:4-14.

8. Robinson LR, Micklesen PJ, Wang L. Strategies for analyzing nerve conduction data: superiority of a summary index over single tests. Muscle Nerve 1998;21:1166-1171.

9. Robinson LR, Micklesen PJ, Wang L. Optimizing the number of tests for carpal tunnel syndrome. Muscle Nerve 2000;23:1880-1882.

10. American Association of Electrodiagnostic Medicine, American Academy of Neurology, American Academy of Physical Medicine and Rehabilitation. Practice parameter for electrodiagnostic studies in carpal tunnel syndrome: summary statement. Muscle Nerve 2002;25:918-922.

11. Keith MW, Masear V, Chung KC, Amadio PC, Andary M, Barth RW, et al. American Academy of Orthopaedic Surgeons. American Academy of Orthopaedic Surgeons clinical practice guideline on the treatment of carpal tunnel syndrome. J Bone Joint Surg Am 2010;92:218-219.

12. Goddard DH, Barnes CG, Berry H, Evans S. Measurement of nerve conduction-a comparison of orthodromic and antidromic methods. Clin Rheumatol 1983;2:169-174.

13. Melvin JL, Harris DH, Johnson EW. Sensory and motor conduction velocities in the ulnar and median nerves. Arch Phys Med Rehabil 1966;47:511-519.

14. Salerno DF, Franzblau A, Werner RA, Bromberg MB, Armstrong TJ Albers JW. Median and ulnar nerve conduction studies among workers: normative values. Muscle Nerve 1998;21:999-1005.

15. Jablecki C, Nazemi R. Unsuspected digital nerve lesions responsible for abnormal median sensory responses. Arch Phys Med Rehabil 1982;63:135-138.

16. Buchthal F, Rosenfalck A, Trojaborg W. Electrophysiological findings in entrapment of the median nerve at wrist and elbow. J Neurol Neurosurg Psychiatry 1974;37:340-360.

17. Stevens JC. AAEE minimonograph \#26: The electrodiagnosis of carpal tunnel syndrome. Muscle Nerve 1987;10:99-113.

18. Stevens JC. AAEM minimonograph \#26: The electrodiagnosis of carpal tunnel syndrome. Muscle Nerve 1997;20:1477-1486.

19. Felsenthal G, Spindler H. Palmar conduction time of median and ulnar nerves of normal subjects and patients with carpal tunnel syndrome. Am J Phys Med 1979;58:131-138.

20. Kimura J. Electrodiagnosis in diseases of nerve and muscle: principles and practices. Philadelphia: F.A. Davis; 1983. p 106-111.

21. Gordon C, Bowyer BL, Johnson EW. Electrodiagnostic characteristics of acute carpal tunnel syndrome. Arch Phys Med Rehabil 1987;68: $545-548$.

22. Ross MA, Kimura J. AAEM case report \#2: The carpal tunnel syndrome. Muscle Nerve 1995;18:567-573.

23. Daube JR, Stevens JC. The electrodiagnosis of carpal tunnel syndrome (a reply). Muscle Nerve 1993;16:798.

24. Carroll GJ. Comparison of median and radial nerve sensory latencies in the electrophysiological diagnosis of carpal tunnel syndrome. Electroencephalogr Clin Neurophysiol 1987;68:101-106.

25. Pease WS, Cannell CD, Johnson EW. Median to radial latency difference test in mild carpal tunnel syndrome. Muscle Nerve 1989;12:905-909. 
26. Nathan PA, Keniston RC, Meadows KD, Lockwood RS. Predictive value of nerve conduction measurements at the carpal tunnel. Muscle Nerve 1993;16:1377-1382.

27. Nathan PA, Meadows KD, Doyle LS. Sensory segmental latency values of the median nerve for a population of normal individuals. Arch Phys Med Rehabil 1988;69:499-501.

28. Malladi N, Micklesen PJ, Hou J, Robinson LR. Correlation between the combined sensory index and clinical outcome after carpal tunnel decompression: a retrospective review. Muscle Nerve 2010;41:453-457.

29. Rivner MH. Statistical errors and their effect on electrodiagnostic medicine. Muscle Nerve 1994;17:811-814.

30. Sander HW, Quinto C, Saadeh PB, Chokroverty S. Sensitive medianulnar motor comparative techniques in carpal tunnel syndrome. Muscle Nerve 1999;22:88-98.

31. Felsenthal G. Median and ulnar distal motor and sensory latencies in the same normal subject. Arch Phys Med Rehabil 1977;58:297-302.

32. Williams FH, Andary MT. Carpal tunnel syndrome: techniques for diagnosis. Rochester, MN: American Association of Neuromuscular and Electrodiagnostic Medicine; 2001. p 1-8.

33. Preston DC, Logigian EL. Lumbrical and interossei recording in carpal tunnel syndrome. Muscle Nerve 1992;15:1253-1257.

34. Preston DC, Ross MH, Kothari MJ, Plotkin GM, Venkatesh S, Logigian EL. The median-ulnar latency difference studies are comparable in mild carpal tunnel syndrome. Muscle Nerve 1994;17:1469-1471.

35. Preston DC, Logigian EL. Lumbrical and interossei recording in carpal tunnel syndrome (a reply). Muscle Nerve 1994;17:360.

36. Trojaborg W, Grewal RP, Weimer LH, Sheriff P. Value of latency measurements to the small palm muscles compared to other conduction parameters in the carpal tunnel syndrome. Muscle Nerve 1996; 19:243-245.

37. Logigian EL, Busis NA, Berger AR, Brunyninckx F, Khalil N, Shahani BT, et al. Lumbrical sparing in carpal tunnel syndrome: anatomic, physiologic, and diagnostic implications. Neurology 1987;37:1499-1505.

38. Lesser EA, Venkatesh S, Preston DC, Logigian EL. Stimulation distal to the lesion in patients with carpal tunnel syndrome. Muscle Nerve 1995; 18:503-507.

39. Dumitru D. Electrodiagnostic medicine. Philadelphia: Hanley \& Belfus; 1995. p 143, 872, 874-875.

40. Marin EL, Vernick S, Friedmann LW. Carpal tunnel syndrome: median nerve stress test. Arch Phys Med Rehabil 1983;64:206-208.

41. Schwartz MS, Gordon JA, Swash M. Slowed nerve conduction with wrist flexion in carpal tunnel syndrome. Ann Neurol 1980;8:69-71.

42. Dunnan JB, Waylonis GW. Wrist flexion as an adjunct to the diagnosis of carpal tunnel syndrome. Arch Phys Med Rehabil 1991;72:211-213.

43. Keith MW, Masear V, Chung K, Maupin K, Andary M, Amadio PC, et al. Diagnosis of carpal tunnel syndrome. J Am Acad Orthop Surg 2009;17:389-396.

44. Rempel D, Evanoff B, Amadio PC, de Krom M, Franklin G, Franzblau A, et al. Consensus criteria for classification of carpal tunnel syndrome in epidemiologic studies. Am J Publ Health 1998;88:1447-1451.

45. Gelberman RH, Hergenroeder PT, Hargens AR, Lundborg GN, Akeson WH. The carpal tunnel syndrome. A study of carpal canal pressures. J Bone Joint Surg Am 1981;63:380-383.

46. Homan MM, Franzblau A, Werner RA, Albers JW, Armstrong TJ, Bromberg MB. Agreement between symptom surveys, physical examination procedures and electrodiagnostic findings for carpal tunnel syndrome. Scand J Work Environ Health 1999;25:115-124.

47. Atroshi I, Gummesson C, Johnsson R, Ornstein E, Ranstam J, Rosen I. Prevalence of carpal tunnel syndrome in a general population. JAMA 1999;282:153-158.

48. Bingham RC, Rosecrance JC, Cook TM. Prevalence of abnormal nerve conduction in applicants for industrial jobs. Am J Ind Med 1996;30:355-361.

49. Werner RA, Franzblau A, Albers JW, Buchele H, Armstrong TJ. Use of screening nerve conduction studies for predicting future carpal tunnel syndrome. Occup Environ Med 1997;54:96-100.

50. Werner RA, Gell N, Franzblau A, Armstrong TJ. Prolonged median sensory latency as a predictor of future carpal tunnel syndrome. Muscle Nerve 2001;24:1462-1467.
51. Nathan PA, Keniston RC, Myers LD, Meadows KD, Lockwood RS Natural history of median nerve sensory conduction in industry: relationship to symptoms and carpal tunnel syndrome in 558 hands over 11 years. Muscle Nerve 1998;21:711-721.

52. Albers JW, Brown MB, Sima AA, Greene DA. Frequency of median mononeuropathy in patients with mild diabetic neuropathy in the early diabetes intervention trial (EDIT). Tolrestat Study Group For Edit (Early Diabetes Intervention Trial). Muscle Nerve 1996;19:140-146.

53. Eversmann WW Jr, Ritsick JA. Intraoperative changes in motor nerve conduction latency in carpal tunnel syndrome. J Hand Surg [Am] 1978;3:77-81.

54. Garland H, Langworth EP, Tavener D, Clark JM. Surgical treatment for the carpal tunnel syndrome. Lancet 1964;1:1129-1130.

55. Hongell A, Mattsson HS. Neurographic studies before, after, and during operation for median nerve compression in the carpal tunnel. Scand J Plast Reconstr Surg 1971;5:103-109.

56. El-Hajj T, Tohme R, Sawaya R. Changes in electrophysiological parameters after surgery for the carpal tunnel syndrome. J Clin Neurophysiol 2010;27:224-226.

57. Prick JJ, Blaauw G, Vredeveld JW, Oosterloo SJ. Results of carpal tunnel release. Eur J Neurol 2003;10:733-736.

58. Yates SK, Hurst LN, Brown WF. Physiological observations in the median nerve during carpal tunnel surgery. Ann Neurol 1981;10: $227-229$.

59. Balbierz JM, Cottrell AC, Cottrell WD. Is needle examination always necessary in evaluation of carpal tunnel syndrome? Arch Phys Med Rehabil 1998;79:514-516.

60. Werner RA, Albers JW. Relation between needle electromyography and nerve conduction studies in patients with carpal tunnel syndrome. Arch Phys Med Rehabil 1995;76:246-249.

61. Chan L, Turner JA, Comstock BA, Levenson LM, Hollingworth W, Heagerty PJ, et al. The relationship between electrodiagnostic findings and patient symptoms and function in carpal tunnel syndrome. Arch Phys Med Rehabil 2007;88:19-24.

62. Katz JN, Larson MG, Sabra A, Krarup C, Stirrat CR, Sethi R, et al. The carpal tunnel syndrome: diagnostic utility of the history and physical examination. Ann Intern Med 1990;112:321-27.

63. Bland JD. Do nerve conduction studies predict the outcome of carpal tunnel decompression? Muscle Nerve 2001;24:935-940.

64. Robinson L, Kliot M. Stop using arbitrary grading schemes in carpal tunnel syndrome. Muscle Nerve 2008;37:804

65. Cannon LJ, Bernacki EJ, Walter SD. Personal and occupational factors associated with carpal tunnel syndrome. J Occup Med 1982;23: 255-258.

66. Nathan PA, Keniston RC, Myers LD, Meadows KD. Obesity as a risk factor for slowing of sensory conduction of the median nerve in industry: a cross-sectional and longitudinal study involving 429 workers. J Occup Med 1992;34:379-383.

67. Werner RA, Franzblau A, Albers JW, Armstrong TJ. Influence of body mass index and work activity on the prevalence of median mononeuropathy at the wrist. Occup Environ Med 1997;54:268-271.

68. Kimura J. The carpal tunnel syndrome: localization of conduction abnormalities within the distal segment of the median nerve. Brain 1979;102:619-635.

69. Andary MT, Fankhauser MJ, Spiegel N, Zaneteas P, Ritson JL, Hulce VD, et al. Comparison of four techniques in the diagnosis of mild carpal tunnel syndrome [abstract]. Muscle Nerve 1992;15:1174.

70. Johnson EW, Kukla RD, Wongsam PE, Piedmont A. Sensory latencies to the ring finger: normal values and relation to carpal tunnel syndrome. Arch Phys Med Rehabil 1981;62:206-208.

71. Jackson DA, Clifford JC. Electrodiagnosis of mild carpal tunnel syndrome. Arch Phys Med Rehabil 1989;70:199-204.

72. Uncini A, Lange DJ, Soloman M, Soliven B, Meer J, Lovelace RE. Ring finger testing in carpal tunnel syndrome: a comparative study of diagnostic utility. Muscle Nerve 1989;12:735-741.

73. Redmond MD, Rivner MH. False positive electrodiagnostic tests in carpal tunnel syndrome. Muscle Nerve 1988;11:511-518.

74. Johnson EW, Sipski M, Lammertse T. Median and radial sensory latencies to digit I: normal values and usefulness in carpal tunnel syndrome. Arch Phys Med Rehabil 1987;68:140-141. 